\title{
Analysis of Optimization Possibilities of Slat Conveyor Drives
}

\author{
DRAGAN Đ. ŽIVANIĆ, University of Novi Sad, \\ Faculty of Technical Sciences, Novi Sad \\ Professional paper \\ UDC: 621.86 \\ NIKOLA T. ILANKOVIĆ, University of Novi Sad, \\ Faculty of Technical Sciences, Novi Sad \\ The paper presents an analysis of the possibility of optimizing the drive of slat conveyors, which \\ primarily refers to the choice of the drive chain and the number of drive units. The basic characteristics \\ of slat conveyors, as a mean of continuous transport, procedures for calculating the basic parameters \\ and the choice of basic elements of the conveyor are presented. Cases with one angular and \\ combinations with several line drive units are considered. In order to observe influential parameters, \\ variants with different route lengths and line weight of transported material were considered. At the end \\ of the paper, the obtained results were analyzed and appropriate conclusions were made.
}

Key Words: slat conveyor, drive optimization, drive chain, drive unit

\section{INTRODUCTION}

Slat conveyors are used for transport of bulk and piece material under difficult working conditions abrasive materials, materials at elevated temperatures, castings, heavy piece materials, etc. These conveyors have found application in various branches of the economy, primarily in mining, metallurgy, chemical and cement industries, in the transport and transshipment of heavy items [1]. Figure 1 shows the schematic view of the slat conveyor.

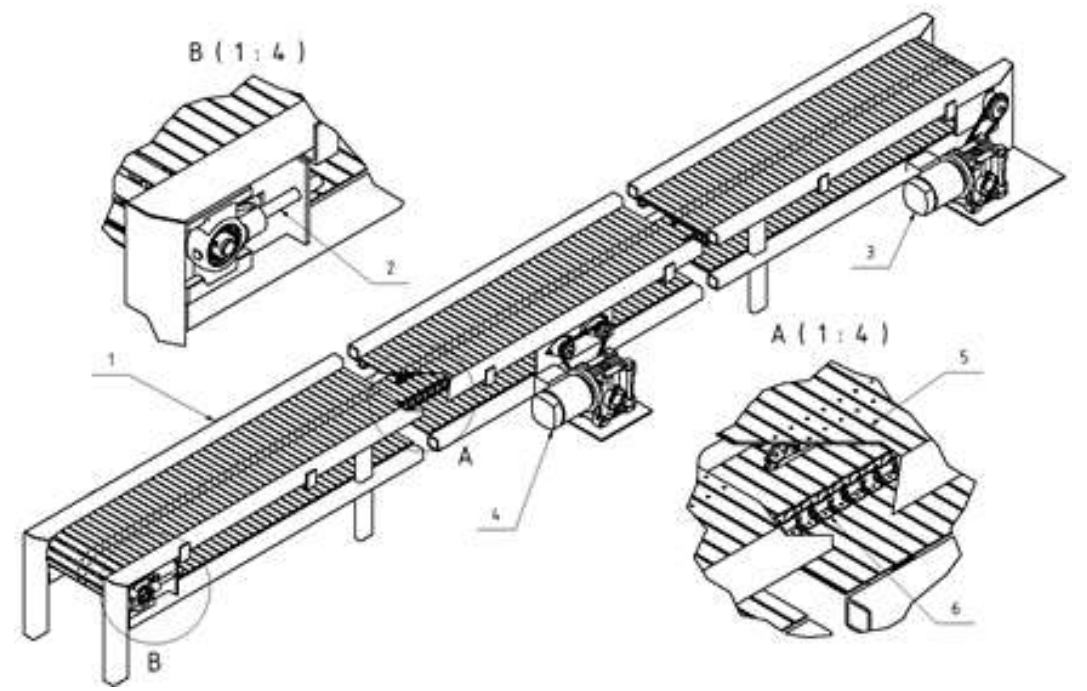

Figure 1 - Schematic view of the slat conveyor

The slat conveyor consists of a supporting structure (1) at the end of which there is an angular drive

Author's address: Dragan Živanić, University of Novi Sad, Faculty of Technical Sciences, Novi Sad, Trg Dositeja Obradovića 6

e-mail: zivanic@uns.ac.rs

Paper received: 04.02.2021.

Paper accepted: 05.12.2021. mechanism with a sprocket (3), and at the other end there is a tension sprocket with a tensioning device (2). Line drives (4) can also be installed. On one or two drive chains (6) the slats (5) representing load carrying elements of the conveyor are fixed. The drive chain with slats has little wheels with bearings in them. The wheels are used in order to avoid sliding friction between the chain and the supporting structure, they provide rolling friction. The material is loaded via one or 
more loading hoppers, which can be placed on any part along the conveyor route when transporting bulk material or the piece material can be loaded on any part of the conveyor. Unloading is done on the end sprocket for bulk material or on any part of the conveyor for piece material. Unloading of bulk material on the conveyor line is performed less frequently and is possible only with those conveyors that have flat slats, without sides, by means of plow unloaders. In general purpose slat conveyors, plate chains are used, which allow arbitrary configuration of the route in the vertical plane. In most cases, two drive chains are used, and for small widths and in specific conditions, one chain can be used.

The drive mechanisms of these conveyors can be divided, depending on the way of transmitting the driven force, into angular - through the drive sprocket, and line - through the so-called central drive [2].

The angular drive mechanism, Figure 2, consists of a drive gear motor (1), power transmissions (2) from the gearbox to the drive shaft and a drive sprocket (3).

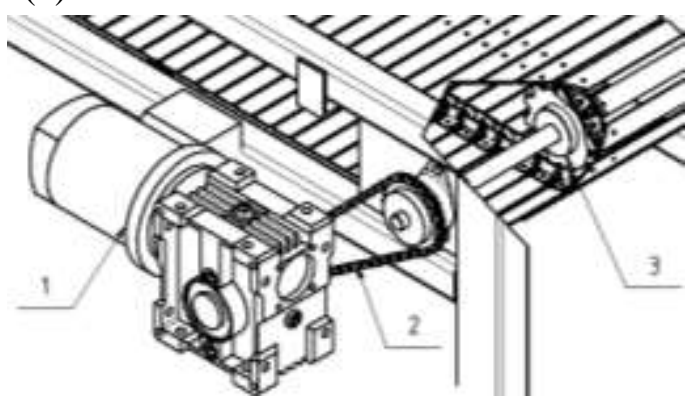

Figure 2 - Angular drive mechanism

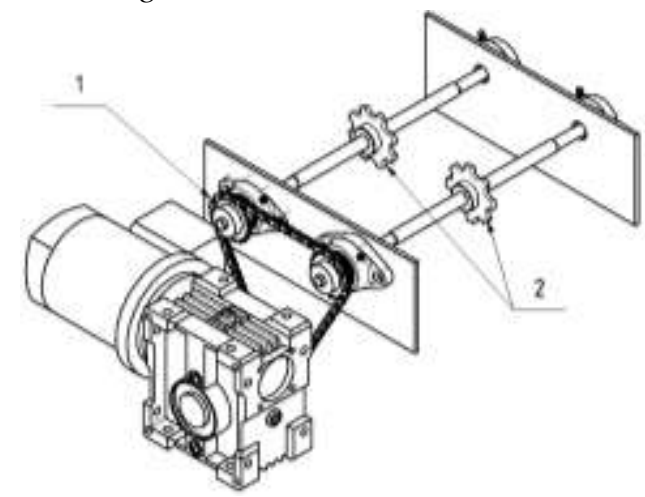

Figure 3 - Line drive mechanism

The linear drive mechanism is shown in Figure 3. Single-sprocket connection is used very rarely, because it requires large tooth heights to ensure continuous contact of at least one tooth with the chain. This problem is solved by using two sprockets (2) whose shafts are connected by a special chain (1), and are placed so that the distance between them is:

$$
L=(n+0,5) \cdot t
$$

where:

- $n$-whole number;

- $t$-chain pitch.

Setting to "half a step" allows more favorable connection and a significant reduction in tooth height.

There are several combinations of the position and number of drive units of plate conveyors - one angular, one line, one angular and one or more line drives, etc.

\section{BASICS CALCULATIONS OF SLAT CONVEYORS}

This chapter presents the procedure for calculating basic parameters of slat conveyors, according to [3], which are capacity, width of material carrying slats, forces in the chain and the required drive power.

\subsection{Determining the capacity of the conveyor and the width of the load carrying slat}

Capacity is the basic characteristic of transport machines and represents the amount of transported material per time unit. When the mass of transported material is evenly distributed per meter of conveyor, the mass capacity is calculated according to:

$$
Q=q \cdot v
$$

where:

- $q$-material line mass;

- $v$ - transport speed.

The width of the load carrying slat depends on whether the slat has sides or not. It is calculated according to:

- slats without sides:

$$
B=\sqrt{\frac{Q}{648 \cdot k_{3} \cdot v \cdot \rho \cdot \tan \varphi}}
$$

- slats with sides:

$$
B=\sqrt{\frac{Q}{900 \cdot k_{3} \cdot v \cdot \rho \cdot(\tan \varphi+4 \cdot \lambda \cdot \psi)}}
$$

where:

- $k_{3}$ - capacity reduction coefficient due to conveyor inclination;

- $\rho$ - density of the material;

- $\varphi-$ dyn. angle of material free fall;

- $\lambda=h / B=0,1 \div 0,3-$ the ratio of the height of the sides and the width of the slat;

- $\psi=0,65 \div 0,85-$ section filling coefficient.

\subsection{Chain selection}

Chain selection is based on the calculated breaking force and chain pitch. Calculated chain breaking force $S_{k}$ is calculated according to:

$$
S_{k} \geq n \cdot S_{r}
$$


where:

- $n$ - degree of security;

- $S_{r}$ - calculated workforce in the chain.

The degree of safety depends on the type of chain, the type of route and the operating conditions. It ranges from 6 to 14. The calculated workforce in the chain is calculated according to:

$$
S_{r}=\frac{1}{K_{p}} \cdot\left(S_{\max }+S_{d i n}\right)
$$

where:

- $S_{\max }-$ max. workforce in the chain;

- $S_{d i n}-$ dynamic force during steady state operation;

- $K_{p}$ - the coefficient of unevenness of load redistribution, for conveyors with one drive chain is 1 , and for conveyors with two drive chains is in the range $1.6 \div 1.8$.

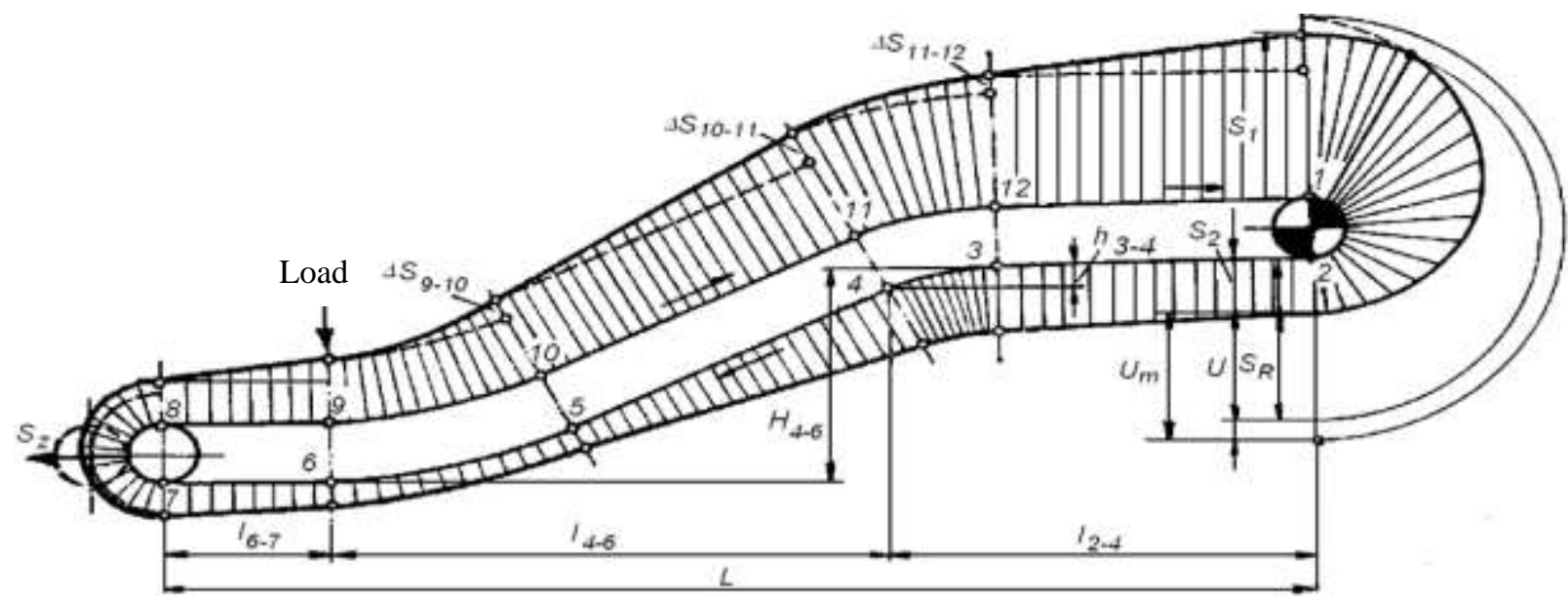

Figure 4 - Schematic overview of force values in the drive element gained by using the outline calculation method

The maximum force in the chain is obtained by the outline calculation method. The method is based on determining the resistance to movement on characteristic sections and on individual elements of the conveyor, as well as calculating the forces in the drive element. It starts from one arbitrarily chosen point and moves in the direction of movement of the drive element.

Therefore, it is necessary to number the characteristic points that define the parts or elements of the conveyor for which it is possible to calculate the magnitude of the resistance to movement, which will be shown in section 2.3. The choice of the starting point is arbitrary, but due to certain conveniences, it is recommended that it be a descending point from the drive element - point 2 in Figure 4.

Starting from the mentioned point, forces are obtained in the marked characteristic points of the drive element, as a function of the force in point 2 :

$$
S_{i}=x_{i} \cdot S_{2}+y_{i}, \quad i=1,2, \ldots, n
$$

where:

- $x_{i}, y_{i}$-numerous factor values that depend on the magnitude of the resistance.

In this way, a system of equations is obtained whose number is one less than the number of characteristic points, i.e., the values of the forces in them. To obtain a solution, it is necessary to introduce another additional condition. For slat conveyors is the prescribed value of the minimum force in the chain, which is in the range of $1 \div 3 \mathrm{kN}$.

The dynamic force at steady state occurs as a consequence of the kinematics of the transmission of motion from the drive sprocket to the drive chain. It is the largest at the moment of coupling the new tooth with the chain pin. Due to the current increase in acceleration, dynamic shocks occur. This change in load has a special effect on the life of the chain because it causes material fatigue. It is calculated according to:

$$
S_{\text {din }}=20 \cdot C_{t} \cdot\left(2 \cdot q_{0}+C_{k} \cdot q\right) \cdot \frac{v^{2} \cdot t}{(z \cdot t)^{2}}
$$

where:

- $C_{t}, C_{k} \leq 1-$ coefficients of influence of chain elasticity and material slip;

- $q_{0}$ - line weight of moving parts of the conveyor;

- $z$ - the number of sprocket teeth.

Based on expression (8), it follows that the dynamic loads are proportional to the square of the speed of movement, which is the main reason for limiting the speed of the conveyor with a drive chain to values less than $1,25 \mathrm{~m} / \mathrm{s}$.

\subsection{Determination of resistance to movement}

Resistances can be divided into longitudinal and local. Longitudinal resistances occur on horizontal, inclined and curvilinear parts of the conveyor. Local resistances occur on sprockets due to friction in their 
bearings and due to chain stiffness, as well as at the unloading point, while resistances at the loading point, due to the low speed of movement, can be neglected.

\subsubsection{Resistances on the linear route}

Determination of resistance on the linear part of the route is performed using an analogy with the rolling resistance of wheels on a deformable surface. It is calculated according to:

work side:

$$
\Delta S=\left(q_{o}+q\right) \cdot l \cdot c \pm\left(q_{o}+q\right) \cdot h
$$

return side:

$$
\Delta S=q_{o} \cdot l \cdot c \pm q_{o} \cdot h
$$

where:

- $\quad l$ - the length of the part of the route being observed;

- $\quad c$-coefficient of resistance depending on the type of chain conveyor;

- $h$ - lifting height;

- sign \pm in front of the second member of the resistance equation depends on whether it is a matter of material raising or lowering.

Orientation value of weight of moving parts of slat conveyors $\left(q_{o}\right)$ is calculated according to:

$$
q_{0}=\left(60 \cdot B+K_{q}\right) \cdot 10
$$

where:

- $B$ - width of load carrying slat;

- $K_{q}$-weight coefficient.

The approximate value of the weight of the moving parts of the slat conveyor is used in the first calculation (first iteration) which results in the choice of the chain. After selecting the chain, it is possible to do the next iteration of the calculation, where the actual value of the weight of the moving parts of the slat conveyor is calculated, based on the data on the selected chain, according to:

$$
q_{0}=q_{l}+\frac{G_{t}}{t_{t}}+\frac{G_{n}}{t_{n}}
$$

where:

- $q_{l}$ - linear weight of the chain;

- $G_{t}$-the weight of the support wheels;

- $G_{n}$-weight of load carrying slats;

- $t_{t}$ - pitch of support wheels;

- $t_{n}$ - pitch of load carrying slats.

Depending on whether piece or bulk material is transported, the weight of the material per meter of conveyor $(q)$ is:

for piece material:

$$
q=\frac{G_{k}}{T}
$$

for bulk material:

$$
q=\frac{Q}{v}
$$

where:

- $G_{k}$ - weight of piece material;

- $T$ - pitch of piece material;

- $Q$ - weight capacity of the conveyor.

\subsubsection{Resistances on the curved route}

Changing the direction of movement of chain conveyors is done with the help of sprockets, deflection batteries and curved guides.

Resistances occurring on the vertical curve are calculated according to:

work side:

$$
\begin{aligned}
& \Delta S=\left|\left(q+q_{o}\right) \cdot l_{k} \pm S_{i} \cdot \alpha\right| \cdot c \\
& \pm\left(q+q_{o}\right) \cdot h_{k}
\end{aligned}
$$

return side:

$$
\Delta S=\left|q_{o} \cdot l_{k} \pm S_{i} \cdot \alpha\right| \cdot c \pm q_{o} \cdot h_{k}
$$

where:

- $l_{k}$ - curve length;

- $S_{i}$ - force in the previous point;

- $\alpha$ - the angle of inclination of the inclined part of the conveyor;

- $h_{k}$ - curve height;

- sign \pm in front of the second member of the resistance equation depends on whether the curve is concave or convex.

The first and second member of expressions (15) and (16) are taken at absolute value because in the case of chain conveyors there are guides on both the lower and the upper side of the support wheels. They represent resistance that depends on the pressure on the support points.

Resistances occurring on the horizontal curve are calculated according to:

work side:

$$
\Delta S=\left(q+q_{o}\right) \cdot l_{k} \cdot c+S_{i} \cdot c_{1} \cdot \alpha
$$

return side:

$$
\Delta S=q_{o} \cdot l_{k} \cdot c+S_{i} \cdot c_{1} \cdot \alpha
$$

where

- $c_{1}$ - resistance to the movement of wheels over guides in a horizontal curve;

- $\alpha-$ the angle of rotation of the route in the horizontal plane.

\subsubsection{Sprocket resistance}

As already mentioned, the resistance on the sprocket occurs due to the resistance in the sprocket bearing and the stiffness of the chain that occurs due to 
the mutual rotation of the links when they pass over the sprocket. It is calculated according to:

$$
\Delta S=2 \cdot S_{i} \cdot \mu \cdot \frac{d_{0}}{D} \cdot\left(\sin \frac{\alpha}{2}+\frac{\mu_{1}}{\mu} \cdot \frac{d_{1}}{d_{0}}\right)
$$

where:

- $\quad \mu$-coefficient of friction in the sprocket bearing;

- $d_{0}-$ the diameter at which friction occurs in the sprocket bearing;

- $\quad D$ - sprocket diameter;

- $\alpha$-span angle;

- $\mu_{1}-$ coefficient of friction on the chain link pin;

- $d_{1}$ - chain pin diameter.

However, since it is difficult to determine the exact value of the coefficient of friction in the sprocket bearing and the chain link pin due to the influence of impurities, the expression is used for practical purposes is:

$$
\Delta S=p \cdot S_{i}
$$

where:

- $\quad p$ - sprocket resistance coefficient ranging in the range of $0.03 \div 0.09$, depending on the span angle.

\subsection{Calculation of the required drive power}

The required power is determined on the basis of the relation:

$$
P=\frac{U \cdot v}{\eta}
$$

where:

- $U=S_{1}-S_{2}-$ circumferential force on the drive sprocket;

- $\quad-$ the degree of utilization of the drive mechanism;

- $S_{1}, S_{2}$ - forces in the chain in points where the chain reaches and leaves the drive sprocket.

\section{ANALYSIS OF VARIANTS OF DRIVE MECHANISM}

As mentioned earlier, there are several variants of slat conveyor drives. In order to determine the influence of individual parameters on the value of the drive power and drive variant, as well as the characteristics of the drive chain, calculations were performed for three combinations of conveyor lengths and line masses of materials.

Considered cases are shown in Table 1, where several drive variants are considered for each case [4].

The abbreviations used are as follows:

- Var. - variant;

- D.T. - drive type;

- R.L. - route length;

- M.P. - mass of pieces;
- A.D. - angular drive;

- L.D. - line drive;

- It. - iteration;

T.P.R. - total power required.

Table 1. Cases of considered conveyors

\begin{tabular}{|l|l|l|l|l|l|l|l|}
\hline & \multicolumn{3}{|l|}{ I case } & \multicolumn{2}{l|}{ II case } & \multicolumn{2}{l|}{ III case } \\
\hline & $\begin{array}{l}\text { Var. } \\
\text { I }\end{array}$ & $\begin{array}{l}\text { Var. } \\
\text { II }\end{array}$ & $\begin{array}{l}\text { Var. } \\
\text { III }\end{array}$ & Var. I & Var. II & $\begin{array}{l}\text { Var. } \\
\text { I }\end{array}$ & Var. II \\
\hline D.T. & $\begin{array}{l}1 \\
\text { A.D. } \\
\text { A.D. } \\
\& ~ 1 \\
\text { L.D. }\end{array}$ & $\begin{array}{l}1 \\
\text { A.D. } \\
\& 2 \\
\text { L.D. }\end{array}$ & $\begin{array}{l}1 \\
\text { A.D. }\end{array}$ & $\begin{array}{l}\text { 1 A.D. } \\
\text { L.D. }\end{array}$ & $\begin{array}{l}1 \\
\text { A.D. }\end{array}$ & $\begin{array}{l}\text { 1 A.D. } \\
\text { L 2 } \\
\text { L.D. }\end{array}$ \\
\hline R.L. & $30 \mathrm{~m}$ & $30 \mathrm{~m}$ & $30 \mathrm{~m}$ & $\begin{array}{l}120 \\
\mathrm{~m}\end{array}$ & $120 \mathrm{~m}$ & $\begin{array}{l}120 \\
\mathrm{~m}\end{array}$ & $120 \mathrm{~m}$ \\
\hline M.P. & $\begin{array}{l}120 \\
\mathrm{~kg}\end{array}$ & $\begin{array}{l}120 \\
\mathrm{~kg}\end{array}$ & $\begin{array}{l}120 \\
\mathrm{~kg}\end{array}$ & $\begin{array}{l}120 \\
\mathrm{~kg}\end{array}$ & $120 \mathrm{~kg}$ & $\begin{array}{l}360 \\
\mathrm{~kg}\end{array}$ & $\begin{array}{l}360 \\
\mathrm{~kg}\end{array}$ \\
\hline
\end{tabular}

A slat conveyor with one drive chain with wheels, length of $30 \mathrm{~m}$ (I case) and $120 \mathrm{~m}$ (case II \& III), respectively, was analyzed. The transported material is piece, mass of $120 \mathrm{~kg}$ (I \& II case) and $360 \mathrm{~kg}$ (III case), which are transported with a pitch between them of $T=2,5 \mathrm{~m}$, transport speed of $v=0,2 \mathrm{~m} / \mathrm{s}$. For all cases, the minimum force in the chain is $S_{\min }=$ $2000 \mathrm{~N}$, the width of the load carrying slat is $B=$ $275 \mathrm{~mm}$, the coefficient of moving resistance is $c=$ 0,03 , the coefficient of resistance of the sprocket is $p=0,07$, he degree of utilization of the drive mechanism is $\eta=0,73$ and the degree of safety of the chain is $n=7$. Schemes of the analyzed variants of the conveyor drive are shown in Figure 5.
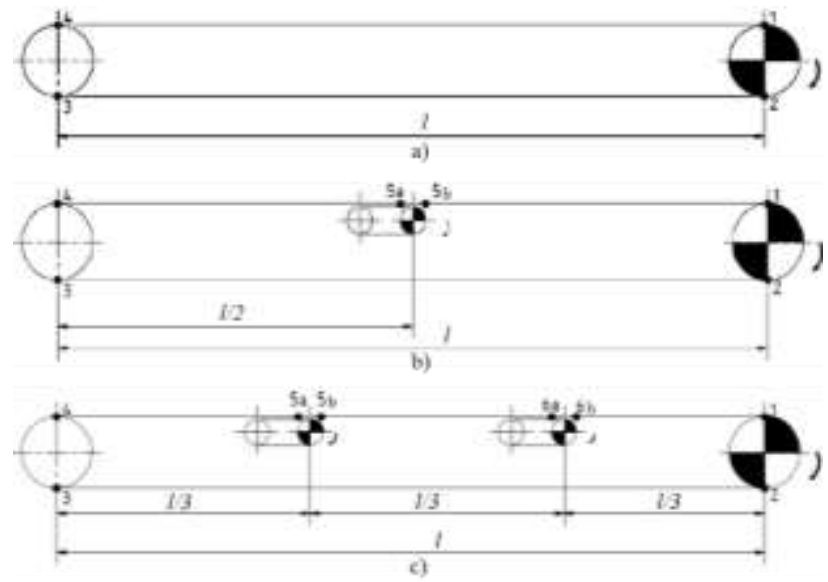

Figure 5 - Schemes of the analyzed variants of the conveyor drive with marked characteristic points - a) conveyor with one angular drive; $b$ ) conveyor with one angular and one line drive; c) conveyor with one corner and two line drives

The calculations were made on the basis of expressions given in Chapter 2, through several iterations in 
order to provide the possibility of choosing the chain with satisfactory characteristics. In the first iteration of the first variant of each of the three cases, the recommended orientation weight of the moving parts of the conveyor was used, where the weight coefficient was used $K_{q}=60$.

When several iterations of the first variant resulted in an optimal, i.e., chain that had sufficient breaking force and a smaller unit mass, that chain was used for the first iteration of the next variant, where again through new iterations it was checked whether it was possible to adopt an even more favorable chain. By adopting a chain of lower line mass, the mass of the moving parts of the conveyor is also reduced, which directly affects the resistance to movement. The chains were adopted from the SKF catalog [5].

\section{RESULTS}

After the calculation, the obtained results were analyzed and grouped. Table 2 shows the obtained results of the calculated workforce in the chain, and

Table 2. Calculated workforce in the chain [N]

\begin{tabular}{|l|l|l|l|l|l|}
\hline & & It. I & It. II & It. III & It. IV \\
\hline \multirow{4}{*}{ I case } & Var. I & 4755 & 2772 & 2764 & - \\
\cline { 2 - 7 } & Var. II & 2519 & 2518 & - & - \\
\cline { 2 - 6 } & Var. III & 2440 & - & - & - \\
\hline \multirow{2}{*}{ II case } & Var. I & 10305 & 4501 & 4421 & 4402 \\
\cline { 2 - 7 } & Var. II & 3360 & 3149 & 3096 & 3062 \\
\hline \multirow{2}{*}{ III case } & Var. I & 13285 & 8210 & 8206 & 8203 \\
\cline { 2 - 6 } & Var. II & 4668 & 4430 & 4368 & 4358 \\
\hline
\end{tabular}

Table 3. The required drive power [W]

\begin{tabular}{|c|c|c|c|c|c|c|}
\hline & & & It. I & It. II & It. III & It. IV \\
\hline \multirow{8}{*}{ I case } & Var. I & A.D. & 547 & 183 & 171 & - \\
\hline & \multirow{3}{*}{ Var. II } & A.D. & 65 & 65 & \multirow{3}{*}{ - } & \multirow{3}{*}{ - } \\
\hline & & L.D. & 114 & 114 & & \\
\hline & & T.P.R. & 179 & 179 & & \\
\hline & \multirow{4}{*}{ Var. III } & A.D. & 43 & \multirow{4}{*}{-} & \multirow{4}{*}{ - } & \multirow{4}{*}{ - } \\
\hline & & 1. L.D. & 93 & & & \\
\hline & & 2. L.D. & 43 & & & \\
\hline & & T.P.R. & 179 & & & \\
\hline \multirow{5}{*}{ II case } & Var. I & A.D. & 2073 & 660 & 608 & 608 \\
\hline & \multirow{4}{*}{ Var. II } & A.D. & 183 & 178 & 173 & 172 \\
\hline & & 1. L.D. & 289 & 279 & 264 & 256 \\
\hline & & 2. L.D. & 183 & 178 & 173 & 172 \\
\hline & & T.P.R. & 655 & 635 & 610 & 600 \\
\hline \multirow{5}{*}{ III case } & Var. I & A.D. & 3021 & 1653 & 1614 & 1583 \\
\hline & \multirow{4}{*}{ Var. II } & A.D. & 504 & 495 & 491 & 489 \\
\hline & & 1. L.D. & 632 & 603 & 587 & 585 \\
\hline & & 2. L.D. & 504 & 495 & 491 & 489 \\
\hline & & T.P.R. & 1640 & 1593 & 1569 & 1562 \\
\hline
\end{tabular}

Table 3 shows the power required to drive the conveyor, for different cases and variants of the conveyor drive. The "-" sign in the table means that after a certain iteration, there was no weaker chain in the catalog for further iterations.

\section{DISCUSION}

The results of the experiment showed that through more iterations of the calculation and using a combination of angular and line drives, it is possible to choose a drive chain that has lower breaking force than in the case if the calculation was completed after the first iteration (in the III case up to 4 times). The largest decline in the calculated workforce in the chain occurs after the first iteration when in the second iteration the data of the previous chosen chain is used. The reason for this is that in the first iteration, the approximate value of the weight of the moving parts of the slat conveyors is used. Also, with the introduction of line drives, there is a decline in the calculated workforce in the chain, compared to the case when only the angular drive is used.

As for the required power of the conveyor drive, it was shown that it decreases with iterations, because in each subsequent iteration, a previously adopted chain of lower line weight was used. With the introduction of line drives, the required individual power of each drive unit is less than the required drive power in the case when there is only an angular drive, but in total the power remains approximately the same.

\section{CONSLUSION}

The obtained results indicated the importance of calculating the basic parameters of slat conveyors through several iterations, because this can primarily lead to the selection of the optimal chain. Also, it can be concluded that the introduction of more drive units, instead of one angular, leads to a more optimal chain. This is especially pronounced with the increase in the length and line weight of the transported material. As for the required power, it can be concluded that the total required power was not significantly reduced by the use of more drives, compared to one angle drive.

Therefore, when choosing the type and number of drive units, a more detailed techno-economic analysis must be performed, which would show whether the choice of a more optimal chain justifies the use of more drives. The use of one drive of higher power causes the use of shafts of larger diameter, bearing capacity, transmission chain pairs of higher load bearing capacity, etc. However, by increasing the number of drive units, the total number of power transmissions and supporting elements increases, and thus the complexity of the conveyor itself rises. 
The direction of further research, in terms of selecting the number and types of drive units of slate conveyors, should include a complete techno-economic analysis, which after calculation and selection of all elements, would take into account investment, but also operation and maintenance costs for different variants drive. Only after that, a complete picture could be obtained, which would show how much, and whether it is at all, economically and technically justified to introduce additional line drive units.

\section{REFERENCES}

[1] Živanić D. Neprekidni i automatizovani transport, script, University of Novi Sad, Faculty of Technical Sciences, Novi Sad, R. Srbija, 2020.
[2] Colijn H. Mechanical Conveyors for Bulk Solids, Elsevier, Amsterdam, The Netherlands, 1985.

[3] Spivakovsky A, Dyachkov V. Conveyors and Related Equipment, Central Books, London, UK, 1966.

[4] Jošić D. Analysis of the Use of End Drive and Central Drive in Plate Conveyors, bachelor thesis, University of Novi Sad, Faculty of Technical Sciences, Novi Sad, R. Srbija, 2020.

[5] SKF Conveyor chains, SKF Group, 2013 [cited 19.01.2021].

[6] Available on: https://bit.ly/3sxKCxr

\section{REZIME}

\section{ANALIZA MOGUĆNOSTI OPTIMIZACIJE POGONA PLOČASTIH TRANSPORTERA}

U radu je prikazana optimizacija pogona pločastog transportera. Optimizacija je bazirana na izboru optimalnog vučnog lanca i potrebne snage za pogon transportera. Razmatrani su slučajevi sa jednom ugaonom pogonskom jedinicom, kao i slučajevi sa jednom ugaonom i više linijskih pogonskih jedinica kako bi se utvrdilo koja varijanta pogona je najefikasnija. U razmatranim slučajevima se menjala dužina trase i težina komadnog materijala. Na početku rada su date osnovne karakteristike pločastih transportera kao sredstva za neprekidni transport. Zatim su prikazani matematički modeli na osnovu kojih se vrši proračun i izbor osnovnih elemenata transportera. Na kraju je opisan matematički eksperiment i razmotreni su dobijeni rezultati.

Ključne reči: pločasti transporter, optimizacija pogona, vučni lanac, pogonska jedinica 